\title{
Trigger finger in adults
}

\author{
Tiffany N.S. Ballard MD, Jeffrey H. Kozlow MD MS
}

\section{Trigger finger occurs most commonly in the fifth and sixth decades of life}

The lifetime risk is about $2 \%$ to $3 \%$, with women affected more frequently than men. The risk is as high as $10 \%$ among people with diabetes mellitus. The ring finger and thumb are most frequently affected. ${ }^{1}$

Injection of corticosteroid is generally accepted as first-line therapy

Corticosteroid injection is inexpensive and easy to perform, and it carries low risk. ${ }^{2}$ The steroid (e.g., dexamethasone or triamcinolone) is typically mixed with a local anesthetic such as lidocaine. Aseptic technique is used to inject the steroid-lidocaine mixture into the flexor tendon sheath, at the midline of the flexor crease at the base of the digit. The corticosteroid should not be injected directly into the tendon, as this increases the risk of tendon rupture. Studies have been inconclusive as to which steroid is most effective. ${ }^{2}$ Splinting is an option for patients who are opposed to corticosteroid injection; this approach is more effective when triggering has been present for less than six months. ${ }^{3}$

A video showing a patient with untreated symptomatic triggering of the left thumb is available in Appendix 1, at www.cmaj.ca/ lookup/suppl/doi:10.1503/cmaj.150225/ -/DC1.
Impaired gliding of the flexor tendon at the first annular pulley leads to triggering

Patients present with symptomatic locking during flexion and extension of the affected digit, as the tendon catches on the stenotic pulley (see video, Appendix 1, www.cmaj.ca/lookup/suppl/doi:10.1503/ cmaj.150225/-/DC1). The first annular pulley (A1) is located over the metacarpal head in the palm (Figure 1).

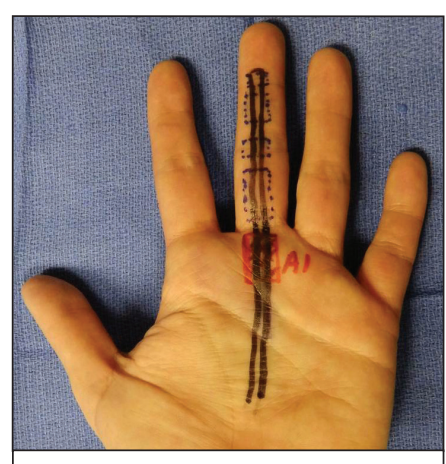

Figure 1: Location of the A1 pulley of the middle finger.
Recurrence of triggering is common, even after corticosteroid injection

Success rates after one injection range from $67 \%$ to $90 \%$, with treatment of the thumb being most successful. The recurrence rate is higher (about 50\%) among patients with diabetes than among those who do not have diabetes. ${ }^{4}$ After two injections, the overall effectiveness decreases. ${ }^{5}$

\section{References}

1. Makkouk AH, Oetgen ME, Swigart CR, et al. Trigger finger: etiology, evaluation, and treatment. Curr Rev Musculoskelet Med 2008;1:92-6.

2. Ring D, Lozano-Calderón S, Shin R, et al. A prospective randomized controlled trial of injection of dexamethasone versus triamcinolone for idiopathic trigger finger. J Hand Surg Am 2008;33:516-22.

3. Newport ML, Lane LB, Stuchin SA. Treatment of trigger finger by steroid injection. J Hand Surg Am 1990;15:748-50.

4. Griggs SM, Weiss AP, Lane LB, et al. Treatment of trigger finger in patients with diabetes mellitus. J Hand Surg Am 1995;20:787-9.

5. Dala-Ali BM, Nakhdievani A, Lloyd MA, et al. The efficacy of steroid injection in the treatment of trigger finger. Clin Orthop Surg 2012;4:263-8.

6. Wang J, Zhao JG, Liang CC. Percutaneous release, open surgery, or corticosteroid injection, which is the best treatment method for trigger digits? Clin Orthop Relat Res 2013;471:1879-86.

\section{Operative treatment is indicated if conservative treatment fails}

Operative treatment is also indicated if the digit is locked and not reducible. Surgical management, involving percutaneous or open release of the A1 pulley, has a success rate of nearly $100 \%$. Percutaneous release has gained popularity recently because of benefits that include shorter procedure time and quicker recovery of function. Several randomized controlled trials have shown that percutaneous release is as safe and effective as open release. ${ }^{6}$

Competing interests: None declared.

This article has been peer reviewed.

Affiliation: Section of Plastic Surgery, University of Michigan, Ann Arbor, Mich.

Acknowledgement: The authors would like to acknowledge Dr. Steven Haase for helping to make the video that accompanies this article.

Correspondence to: Jeffrey H. Kozlow, jkozlow@med.umich.edu

CMAJ 2016. DOI:10.1503/cmaj.150225 